\title{
Searching and Researching for Located Narratives as Data of the 'Other'
}

\author{
Esita Sur ${ }^{\dagger}$
}

\section{Abstract}

In social science research, methodology plays a significant role in constructing and shaping knowledge; the domain of methodology is equally contested and politicised. Therefore, studying gender and disability has been challenging, as it carries a Western, masculine and objective context. The paper tries to argue that the notions of gender and disability demand a more contextualised and embedded methodologies, which can highlight the possibility of multiple truths and situated knowledge of the marginalised. It also voices a need for a more indigenous methodology to address the questions on gender and disability in India; however, it does neither reject the western canons of work nor the non-indigenous researchers but opens up a more embedded way of thinking.

Keywords: Indigenous Method, Muslim Women, Disability Movement and Identity

\footnotetext{
${ }^{\dagger}$ Assistant Professor in Political Science, Scottish Church College, Kolkata, Email: esitasur@rediffmail.com (C)2019 Sur. This is an Open Access article distributed under the terms of the Creative Commons Attribution License (http://creativecommons.org/licenses/by/2.0), which permits unrestricted use, distribution, and reproduction in any medium, provided the original work is properly cited.
} 


\section{Introduction}

Researching gender, more specifically Muslim women and disability in the Indian context has always been challenging. The task of restoring the 'voices' of the marginalised has been very challenging too; most importantly, do they have any 'voice'? Many leading academicians (Spivak, 1988; Mohanty, 2003) have raised this question. The initiative for this paper comes from two sources: a) my encounters with Muslim women's various forms of experiences based on marginality and discriminations. It has been part of my PhD fieldwork on 'Evolving Activism among Muslim Women in Mumbai Since the 1980s'. b) Moreover, my direct encounters with disabled persons in family and workplace have driven me to revisit the issues of marginality and voicelessness from a different perspective. The use of the terms- searching and researching- has been purposeful in the sense that there is not a dearth of literature and data on the marginalised. The narratives of the participants of my research propelled me to ponder over the dominant stereotypes on Muslim women as passive victims; it enabled me to understand the complicated as well as diverse negotiations that these women do with their identity, culture and patriarchy. In this context, Cora Weber and Pillwax's observation sounds more appropriate (1999): the purpose, appropriate choice and form of research determines the content and methodology of research (Weber and Pillwax, $1999,37)$. The question looms over: is all the data coming from their locations and experiences? Therefore, there has been a need to articulate their knowledge from the bottom. However, the arena of methodology, despite of not being an expert, becomes an area of my concern due to a realisation that researchers in Women's Studies have a common understanding on gender and feminism but what we lack is a similar methodological language to understand each other's work. The reading of Saba Mahmood's Politics of Piety (2005), which focused on Egyptian Muslim women's Dawa movement (Mosque movement) compelled me to think about the different languages on methodology. A very different understanding of Islamic subjectivity and agency of women in Egypt highlights that different methodological approaches are required to understand contextualised negotiations of women (Mahmood, 2005). More specifically, an understanding of politics, culture and economy is needed to comprehend the nature of the Dawa movement in Egypt. The wide gap between the mosque movement in Mumbai (Maharashtra) and Dawa movement in Egypt asks for a need to evolve an indigenous methodology ${ }^{1}$ for retrieving contextualised narratives and perspectives.

In my research and proposition, the term indigenous methodology has been used to throw light on a contextualised understanding of the problems and representation of the marginalised. As Weber and Pillwax (1999) mentions that the notion of indigenous research includes the following principles: a) the interconnectedness of all living things; b) the impact of motives and intentions on person and community; c) the foundation of research as lived indigenous experience; d) the transformative nature of research and the groundedness of theories in Indigenous epistemology (Weber and Pillwax, 1999, 31). In India, Muslim women are always perceived as a homogenous category in terms of their victimhood and disabled persons' experiences are still sidelined in research and academic discourses. Therefore, the role of specific socioeconomic and political contexts becomes crucial in knowledge building and needs to be

\footnotetext{
${ }^{1}$ The Maori Scholar, Linda. T. Smith's work Decolonizing Methodology: Research and Indigenous Peoples Influences (1988) the concept of indigenous methodology, as her work on the Kauppa Maori community (tribal community) has served as an impetus to generate the need not only to have an indigenous methodology but also challenge the scientific framework of research that has served a particular academic community (powerful and Western) for producing knowledge on indigenous people of New Zealand. It always had a background of colonialism and imperialism of knowledge and power.
} 
recognised to challenge the modes of Western knowledge on Muslim women and disabled persons in India. Especially, in the case of Muslim women, the atmosphere of Islamophobia and anti-minorityism to a large extent has jeopardised their lived experiences of survival, resistance and activism.

The argument of the paper is- the Western methodologies have contributed a lot in opening up the new horizons of knowledge and unearthing the experiences of the research participants in the context of non-Western societies, but we need to innovate and expand the horizons of methodologies appropriate for the study in our context. These methodologies can deal with the complexities embedded in our situations and narratives. The paper tries to raise another question: what are the methodological nuances that need attention for addressing these marginal voices? The domain of research methodology has still been influenced by the Western approach based on the superiority of objective and scientific knowledge, which always produces the reductionist views on women and differently abled persons as 'others' and projects them as a unitary category (Smith, 1999, 58-63). The dominant literature on gender and disability revolves around the notion of victimhood and sidelines the question of resistance, negotiation as well as agency of these persons; it also ignores the issue of intersectionality that locates experiences in the matrix of caste, class, gender and ethnicity. Therefore, the epistemological shift should be addressed at two levels: a) at the level of experience and voice, b) at the level of context and knowledge creation. The paper will try to raise a few important questions: A) do we need a separate methodology or method to address the questions on gender and disability? B) What should be the epistemological foundation for a more gender-sensitive method? C) How does this existing literature on women's studies and disability address the method of knowledge building? In this way, the paper will try to discuss the various dimensions of gender and disability in methodological realms and establish a link between theory and lived experiences of these persons.

\section{Epistemology, Methodology and Women Studies}

Epistemology deals with the ways of knowing and also discerning limits and validity of knowledge. At the epistemological level, the nature of traditional social science research has always been masculine. The influence of Western-Colonial knowledge has always considered that the components like gender and politics tend to pollute the purity of the scientific data. Therefore, the definition of data needs to be reinvestigated. The main features of scientific knowledge revolve around empiricism, experimentation, generalisation and prediction. Scientists had developed faith in the positivist method. The principle of objectivity and neutrality-that determines the relationship between the researcher and the subject- has remained very significant (Somekh and Lewin, $2012,3-6)$. The positivists believed that faith in methods was the only path to actual knowledge. However, Lyotard (1984) made it clear that knowledge cannot be reduced to a science, as some of the knowledge comes from experiences, human values and social interactions. Therefore, knowledge can be based on both: empiricism and narratives (Mcnabb, 2004, 7-10). In this context, the definition of methodology revolves around the ways of teaching and studying an area of concern. The process of decolonisation is also crucial to question the validity of Eurocentric knowledge, and it asks for culturally acceptable approaches to study the local and grounded. It always highlights a need for an indigenous methodology that keeps a distance from Western epistemology that exercises power and control over knowledge production; it also leads to the disempowerment of the marginalised by ignoring their voices, histories and agency (Porsanger, 2004).

In this context, the rise of feminist research methodology addresses the first question: a) do we need a separate methodology or method to address the questions on gender and disability? The core of feminist research methodology emphasises the role of gender as an analytical category and women's experience as a valid and authoritative source of knowledge building. 
Therefore, the epistemological challenge lies not in methods but in the source of knowledge that establishes women as actors and agents of change. Therefore, it is not only knowledge but also locating power behind knowledge construction and production on women's lives. The key development in feminist research methodology took place through Sandra Harding's (1987) Standpoint theory. She argued that marginalised people have different perspectives based on their struggle and experiences. These subjugated versions, which have been sidelined for long, can also challenge dominant accounts. These standpoint theorists' work defined the link between social location, women's experiences, and their epistemic perspectives. According to this methodology, women as a subjugated group have specific experiences that have been overlooked and sidelined for long. These voices have to be privileged in knowledge production (Burns and Chantler, 2011). The paradigm of disability studies in India demands more academic exploration than it receives presently. In the words of Rajeev Reddy (2011), multiple approaches are addressing this issue. Emphasis has always given on the medical and rehabilitation approaches. There has also been a shift from this medical approach to social welfare approach to human rights and entitlement approach. However, what remains problematic is to trap the voices of sufferings and lived experiences; moreover, a necessary step to locate the contributions and achievements of the disabled persons should be taken.

Most importantly, the socio-economic and political contexts play a very important role to shape the issue of disability and women's studies. Nida Kirmani's work (2013) shows that the interests of Dalit and Muslim women have hardly found any representation in the mainstream women's movement. Addressing Muslim women's issues within the mainstream women's movement has been a challenging job. It shows the necessity to understand the role of difference and intersectionality in their experiences (Kirmani, 2013, 4-6). According to Gabriel Dietrich (2008) and Flavia Agnes (2008) the nature of the women's movement as a promiddle class, was perceived as a part of a Hindu majoritarian thought, which to a large extent failed to understand the subjugation of women based on caste, community, class and religion(Agnes 2008, 505-506). Samita Sen, Nandita Dhawan and Nirmala Banerjee (2002), mentions that if the 1970s and 80s were an age of exploration, the 1990s was an age of doubt and reflection. The political polarisation over Mandal-Masjid issue unsettled the discursive context within which questions of women's rights and gender equality had been formulated. The evidence of upper caste and middle-class women's opposition to affirmative action for disadvantaged castes as evidence of caste-class figures among women, and was a challenge to the political possibilities of a singular feminist gender-speak (Sen and Dhawan, 2011, 12-14). Flavia Agnes (2008) has countered that in the 1970s and 80s women's movement started using the Hindu religious symbols and ideas to counter the claims that Feminism was Western and inapplicable in India. The movement adopted a populist approach and relied upon mythical symbols of 'Shakti' and 'Kali' to convey the newly constructed feminist ideology. The intention was not to propagate Hindu ideology, but Christian, Muslim, and other religious minority women felt isolated (Agnes, 2008, 501). The paradigm of methodology must address these nuances and voices and the need for indigenous research methodology in which the nature of being and reality opens up the new avenues for knowledge generation. It may also be different from those that are 'familiar with the scientifically accepted' in Western research (Porsanger, 2004).

\section{Methodological Challenges of a Non-Muslim and Abled Researcher}

The question of positionality, objectivity and situatedness seems to be most significant in addressing the methodological challenges for studying gender and disability. These questions become very important for my PhD fieldwork on Muslim women's organisations. The debate between insider and outsider, perhaps, revolves around identity politics, which serves as a form of ideological positioning and also introduces 
essentialist homogeneity within each category. However, the collective identity politics, along with ideological positioning remains a significant tool for women for understanding material and political realities. It is important to keep in mind that this debate cannot be fixed. The first methodological challenge that I faced was regarding the question of positionality in the research. The training I received in research methodology taught me: research is not a technical enterprise; rather there are other dimensions of research practices-personal, social and ideological (Macnabb, 2004). Being a Hindu, studying Muslim women's lives provoked not only my 'outsider' identity in the community but also a power hierarchy that prevails over the mainstream. Therefore, the process of searching for narratives of the other is also related to power politics and the location of the researcher. The same binary between abled and disabled and the positionality of the researcher also becomes relevant in disability research. Another challenge is the question of the authenticity of the researcher and the data produced by the researcher in this insideroutsider debate. The political aspect of identity positionings is revolving around the question of authenticity. There is a more complex intersection between indigenous research, diverse positionings and subjectivity of the researcher (Kovach, Carrieere, Barrett, Montgomery and Gillies, 2013, 490).

This methodological challenge, to some extent, can be overcome by the method of shifting and rooting as propagated by Yuval-Davis (2011) and the Italian transversals. ${ }^{2}$ We all have to root in a particular set of methods learned within traditional disciplines, and methodological shifting is all about challenging one's racism, classism, ableism, and community location; it remains good practice for producing meaningful

\footnotetext{
2 Transversal politics credits the term "transversal politics" to a group of Italian feminists who organised a meeting in 1993 in Bologna between Palestinian and Israeli women. It emerged as an alternative to universalism, which becomes more exclusive instead of being inclusive, as it adopts a homogenous point of departure to explain women's lives. Transversality emerged as an alternative to identity politics. The problem with identity politics is that it is
}

cross-cultural and identity dialogue. Shifting does not mean losing one's rooting and set of values, but the process of shifting should not homogenise the other. However, it is not an easy process. In the early days of research, my methodological rooting was in quantitative research; my interest in women's studies later motivated me to shift to feminist research methodology. This shift not only enabled me to value women's experience as a category for analysis but also provided the prism to locate complications and nuances within women's experience. One of important methodological challenges was to deconstruct Muslim women as a homogenous category and address the questions of agency and victimhood at different levels of lived experiences and negotiations through their collective and individual activism. The direct encounters with my respondents always helped to bridge the gap between human voicelessness and agency.

In disability research, the same challenge lies, but it becomes further nuanced on the issue of construction of disability as normal versus abnormal as well as biological-medical and socio-cultural constructions. Disability as a matter of concern has not received its due attention for long; especially the way gender, caste and class have dominated academic discourses. Recently, impairment has been considered as a subject for research. According to Erving Goffman (1963), exclusionary practices are always there against persons with impairments, as society plays an important role in constructing the meanings of able and disable. The social model has criticised the biological and medical models(Reddy, 2011, 289-290). Since the 1980s, the disability rights activists in North America and Europe began to oppose the dichotomous and reductionist paradigm of normal and non-normal. The social model

associated with ideological positioning that assumes essentialist homogeneity within each category. This does not allow us to look at the politics of difference under the rubric of identity politics. However, the challenge of transversalism is to address the dilemma: can women go beyond collective identity politics without losing their ideological positioning? (Pryse, 2000,108-109). 
sharply questioned the organisation of biological differences into social constructions, which are rooted in power-knowledge relations; it also tried to separate impairment from disability and treated these two as mutually exclusive. However, this model has provided enough political impetus in the disability rights movements but not free from shortcomings. According to Simi Linton (1998), the prefix (dis) connotes a separation between ability and its absence. Therefore, it signifies an act of repudiation of ability by society, not always the biological condition located within the individual (Reddy, 2012, 289).

The second and third methodological challenges are intertwined and revolve around the question of researcher's objectivity, subjective experiences of the researched and its impact on knowledge building. Feminist Standpoint theorist Donna Haraway (1988) defined feminist objectivity in terms of situated knowledge that enables us to situate assumptions, limitations and political and social influences of any creative project; it also enables us to dismantle our conventional ideas on gender, women, disability and sexuality and evolve an alternative reading strategies for understanding situated knowledge and subjectivity beyond the confines of identity politics. In this context, women's multiple standpoints have been a source for knowledge building. Sandra Harding (1987) also suggests the possibility of 'strong' and 'weak' objectivity and that objectivity is stronger if the researcher exposes the cultural and biographical aspects of the research and weaker if they do not (Harding, 1987). Moreover, the researcher's socioeconomic locations and values need to be incorporated. In a nutshell, the idea of contextualised objectivity poses a challenge to the traditional definition of scientific objectivity. My semi-structured in-depth interviews with Muslim women activists and members of

\footnotetext{
${ }^{3}$ Edward Said coined the term Orientalism. It is the way the West looks at the East, better to say portrays the culture, history and art though their eyes and locations. Said mentions that subtle and persistent Eurocentric biases against Arab-Islamic people is related to the colonial and imperial justification of European countries that come from a long tradition of false and romantised
}

organisations have always helped to understand their multilayered experiences of negotiations and resistance to patriarchy. The traditional male-dominated, as well as a positivist social science research, has always followed a reductionist approach to produce Muslim women as the other. The influence of orientalism ${ }^{3}$ has played a significant role in shaping the notion of victimhood of the other. The central question has always been: who is constructing whose social reality and from where?

Moreover, the influence of neutral and objective knowledge has always been significant in defining the binary between normal and abnormal; the domain of objective and scientific knowledge has disregarded the subjective indicators too. As mentioned by Myfanwy Franks (2002), the objectification of other women or the disabled person is another much-discussed issue particularly associated with power relations. It has been regarded as a masculine preoccupation that necessitates a power relation, but the problem is that sometimes it is complicated to avoid the power structures in which we live and work. The techniques like 'listen to the material' or 'letting her speak' also involves an unavoidable power position in the research process (Myfanwy, 2002). At the methodological level, the idea of the researcher as a full non-disabled individual and his or her perceptions of social reality continue to shape the nature of social science research. The intersection of caste, class, gender and disability adds further baggage. Even our notion of subjects also excludes people with impairments and disabilities. For a more extended period, marginals (read women, Dalits, LGBTQ community and minorities) were excluded from the conventional definition of the subject (Mehrotra, 2012, 71-72; see also, Kakoti Borah, 2018). Therefore, research on disability becomes

images of Asia and Middle East as backward and uncivilised. However, Edward Said's work is not free from criticisms, as many scholars had highlighted that his account has factual and methodological errors. In spite all these, contribution of Edward Said's work cannot be underestimated (Said, 1978). 
further challenging due to the presence of multiple layers of invisibility and voicelessness. The framing of research questions and adaption of tools is very significant to challenge the inadequacies inherent in dominant masculine social science research; the social and ideological location of the researcher is also crucial in terms of questioning the power dynamics embedded in the process of knowing and known. In this context, Linda. T. Smith's work on Decolonizing Methodologies: Research and Indigenous Peoples (1999) successfully highlights how research and knowledge-building become the site of struggle between the West and the other; constructing knowledge on the other is nothing but a very complex process that takes place through colonialism, imperialism and disciplining the colonial mind. ${ }^{4}$

Therefore, understanding of Muslim women's issues and disable person's rights has to be connected with the broader social movement in India. The socio-political context has always played an important role in shaping these movements like the women's movement, human rights movements and environmental movements. We also cannot ignore the influence of different types of ideologies in these movements. This has created a need to introduce a shift in theory-construction and reformulate methodology for understanding changing reality. Since the 1980s, the emerging social movements had established a link between global networking and local realities. Methodologically, tracing the dynamics and diversity in social movements and implications of colonial discourses on the questions of health, disability and socio-structural inequalities is important. In the South Asian context understanding of disability through charity, religious development, culture-centred and

\footnotetext{
${ }^{4}$ She has also mentioned that the notion of the other and the process of othering have been an integral part of an integral part of modernism. The development of scientific thought, exploration, expansion of trade, establishment of colonies and discovery by the Europeans of the other cultures are multiple facets of modernism. Colonialism and Imperialism are two processes and formations through which the West has seen, known and named the other world and indigenous communities. These
}

kinship-based models have always played a significant role as Miles (2002) said that it is important to recover histories of disability to enable self-help strategies through references to the past (Mehrotra 2012, 70). In the case of Muslim women's issues, the politics of interpretation of the text by the religious leadership takes centre stage in India. There is an integral relationship between gender and religion; religious interpretation of the text plays a significant role.

Moreover, another challenge is to address the issue of invisibility of Muslim women as well as disable persons as the subjects of research in the domain of social science in India; it, perhaps, makes the role of methodology more crucial for delving into such sidelined voices. What needs to be kept in mind: the Western-hegemonic approaches and perspectives restrict focus on not only objectivity and remedies but also the role of diverse contexts and inequalities, that shape the experiences of the marginal from different perspectives. It needs to be addressed. Moreover, essentialism and cultural relativism are considered to be the strongest theoretical weapons in scientific research. The representation of monolithic Muslim women as victims not only overlooks the presence of internal differences but also multiple standpoints on the meanings of Islam and women's rights in diverse contexts. The undocumented histories of struggle and activism of them need to be researched and given visibility. Therefore, the invisibility of Muslim women and disabled persons in research and knowledge production is not a simple process but backed by power and dominant discourses. It necessitates a demand to raise questions on conventional socio-political constructions of

developments enabled the West to make ideological claims regarding its civilizational superiority. It has not only resulted in the imposition of Western authority on the indigenous lands, modes of production, law and government but also on over all aspects of indigenous knowledge, language, cultures and academic disciplines. Therefore, it also involves a power hierarchy in the realm of knowledge building (Smith, 1999). 
Muslim women or disabled person in the Indian context.

\section{Muslim Women's Movement and Disability Rights Movement in India: Multiple Standpoints}

Studying these two arenas of mobilisations in the Indian context demands an understanding of decolonisation of methodology. It enables us to link between theory and praxis. The pivot of feminist research methodology comes from the women's movement. Indian women's movement has faced criticisms for its inclination towards Western Feminism and representation of middle-class women's experiences as dominant narratives. The emergence of Dalit feminism, Islamic feminism and Black feminism paved the way for multiple voices and standpoints and the need that silenced voices should be articulated within feminism (Dietrich, 2008). The rising activism of Muslim women on talaq (divorce) and right to access the sacred spaces (the mosque) in India have created the necessity to revisit the methodological positions by considering the socio-political influences. There are different types of methodological approaches to the study of Muslim women in India. Dominant discursive tropes like triple talaq, burqa (veiling) and polygamy have produced generalised notions on their passivity and victimhood. Evidently, 'veiling' practices of Muslim women have also served as a road to accomplishing one's identity as well as safe access to gendered public spaces (Abraham, 2018; Bhattacharyya and Prasad, forthcoming, in press; Khan, 2007). Another approach is based on the production of the homogenous nature of

\footnotetext{
5 The Bharatiya Muslim Mahila Andolan is a Muslim women's organisation based in Mumbai; it emerged in 2007. This organisation has always raised voices against the practices of talaq and polygamy and fought for Muslim women's rights.

${ }^{6}$ While secular feminism is based upon the rejection and dismissal of religion, Islamic feminism is based upon the revision and reconstruction of Islam. Islamic Feminists argue that Islamic feminism is a movement of women who have maintained their religious beliefs while trying to promote egalitarian ethics of Islam by supporting the female supportive verses of the Quran in their fights for women's rights, especially for women's access to education. It is path of compromise and creative synthesis.
}

the community. It hardly recognises that Muslim women's experiences can be diverse, and they can also be the material subjects of power and resistance (Hasan and Menon, 2005). Chandra Talpade Mohanty's (2003) work has successfully challenged the politics behind the hegemonic knowledge building process on the Third World Women by the West.

Moreover, the atmosphere of Islamophobia after $9 / 11$ has contributed to the generation of stereotyped images and universal notions about the other. These developments have also shaped our methodological approaches as socioeconomic and political influences play a significant role in shaping the nature of research. My research on 'Evolving Activism among Muslim Women in Mumbai Since the 1980s' not only forced me to disturb the stereotyped image of Muslim women as passive victims but also motivated me to understand their struggle and narratives of resistance from their locations. The emerging Muslim women's organisations in India also highlight the presence of multiple standpoints on Muslim women's rights within these organisations. While the BMMA (Bharatiya Muslim Mahila Andolan) ${ }^{5}$ in Mumbai has asked for a ban on the practice of triple talaq, many Muslim women members of the All India Muslim Personal Law Board protested against Muslim personal law reform, as it is an intrusion in their religion and culture(PTI, 2019; also see for details, Sur 2018). Moreover, at a theoretical level, the differences between Muslim, Islamic and Islamist feminists always indicated the presence of multiple standpoints on Islam and women's rights. $^{6}$ It becomes clear that

Mir-Hosseini (1999) argues that Islamic feminism is an indigenous, locally produced feminist consciousness. The emergence of this feminist consciousness is coupled with a context, which is marked by the multiplicity of factors such as globalisation, fragmentation and waves of Islamic revivalism as well as reformation. Since the 1980s, the issue of women in Islamic worlds has been tied to larger issues of Islam's cultural and political assertions. Islamists argue that Islam is a total system and cannot be compartmentalised. Thus, politics, economics and culture must be Islamic. The Islamist approach to gender, to some extent, combines religion and culture. It essentialises and de-historicises them and absolutise cultural differences. This perspective latches on to a particular interpretation 
difference and multiple voices should be considered as the key epistemological stances in research on the marginalised. The 1980s saw a shift in the disability movement in India and the shift is from welfare to development; it also emphasises the need for a rights-based approach(Mondal 2010, 24-25). The Decade of Disabled Persons marked another shift in the whole debate about the goals of rehabilitation. Several factors worked together. The rise of women's movement and the presence of civil society organisations had created conducive space to raise the issues concerning disability. According to Bhambani (2005), three critical factors have been significant in this movement: right-based issues, inclusion-integration issues and demands for services, facilities and concessions. The Persons with Disability Act 1995 has been the most convenient tool for disability activists as they were successful in pushing forward their rights-based approach. It also needs to be mentioned that multiple standpoints, strategies and divisions also mark disability movement. The influence of class and gender can not at all be ignored (Mehrotra 2012,70-72).

\section{Conclusion: A Way Forward for Inclusive Knowledge Building}

The emergence of these movements not only highlights contradictions and conflicts in society but also demands a shift in our methodological orientations. The concept of the critical social core provides the theoretical perspective to explain social movement activism and identity politics. According to Rajendra Sing (2001), the ongoing process of production and reproduction of unresolved social questions and burning issues relating to the problems of social inequalities, subordination of individuals and groups; structures of domination and rule of one over the other-of castes, classes, ethnic groups and genders give rise to social movements (Sing, 2001) Therefore, there has been a link between central social conflicts and movements as it represents the dynamics of social and cultural life. However, a more contextualised methodology will help us in understanding multiple layers of identity politics and activism of the marginalised. The rise of social movements like women's movements, Dalit and tribal and disability rights movements have raised the issues of gender, caste discrimination, human rights violation and social justice; all these issues are only coupled with inequality and marginality and also embody a methodology of viewing society regarding liberation from multiple dominations. However, the concept of secular sectarianism as used by Ajay Gudavarthy and Nissim Mannathukaren (2014) seems to be an interesting concept, which explains that the struggle of the oppressed remains fragmented in India. We can hardly remember an occasion when Dalits and Muslims have raised their voices together. The women's movement, to a large extent, has failed to espouse the problems of Muslim or Dalit women. However, the recent debates on triple talaq have shown: even the voices of Muslim women are not united on the issue of Muslim personal law reform. The difference between the Shia and the Sunni or the Sunni and the Bohra has created internal bifurcations within the category of Muslim women. Concerning disability research, as Anita Ghai (2003) mentions: the disability rights movement in India remains fragmented regarding their rural-urban divisions and class locations (Mehrotra 2012, 68-69). Henceforth, exercising the notion of solidarity in these movements becomes a significant point. Solidarity regarding mutuality, accountability, and the recognition of common interests should be perceived as the basis for relationships among diverse communities. The shift in methodological orientation is also required. According to Shawn Wilson (2001), the Western positivist paradigm has always emphasised the fundamental belief that knowledge is an individual entity. An indigenous paradigm believes that knowledge is relational, and it is based on relational accountability. According to indigenous research methodology, the new types of questions should be asked rather than the questions of validity and reliability (Wilson,

doctrines), and agrees that this is true Islam all about (Hosseini, 1999). 
2001). The methodology adopted for studying disability and Muslim women's rights movements in India must address the politics of location, other socio-economic influences and common issues of marginality and inequality. It demands: being researchers we all should need to think critically about research processes and outcomes and the interests; experiences and subjugated knowledge should come to the centre of research methodologies and construction of knowledge. Therefore, their narratives, stories and lived experiences should be counted as the foundations of research. It also needs to be mentioned that the shift in methodological orientation to study the lives of Muslim women or disable person is also a political act as it initiates a process of selfdetermination of identity. Therefore, multiple sites need to be reinvestigated at the structural, ideological and methodological levels before we start studying the struggle of Muslim women and Disable persons in India.

\section{References}

Abraham, J. (2018). Hindu and Muslim Veiling in North India: beyond the public/private dichotomy. In: Almila A, Inglis D(eds) The Routledge international handbook to veils and veiling practices. Routledge, Oxon and New York, 246-253

Agnes, Flavia (2008). Women's Movement in a Secular Framework: Redefining the Agendas. In: Women's Studies in India: A Reader, edited by Mary.E.John, 501-508. New Delhi: Penguin Books

Bhattacharyya, Rituparna and Prasad Sanjay (forthcoming, in press). Geographies of Indian Women's Everyday Public Safety. In: Rajiv Thakur, Ashok Dutt, Sudhir Thakur, George Pomeroy(eds). Urban and Regional Planning and Development: 20th Century Forms and 21st Century Transformations, USA: Springer

Bhambani, Meenu (2005). The Politics of Disability Rights Movement in India. In: International Journal of Disability Studies, 1 (1) $3-9$
Burns, Diane and Khatidja Chantler (2012). Feminist Methodologies. In: Theory and Methods in Social Science Research, edited by Bridget Somekh and Cathy Lewin, 70-77. New Delhi: Sage Publications

Chakravorty, Spivak Gayatri (1988). Can the Subaltern Speak? jan.ucc.nau.edu. last accessed on 24.02.2019.

Dietrich, Gabriel (2008). Women's Movement and Religion. In: Women's Studies in India: A Reader, edited by Mary.E.John. New Delhi: Penguin Books

Franks, Myfanwy (2002). Feminisms and Crossideological Feminist Social Research: Standpoint, Situatedness and Positionality Developing Cross-ideological Feminist Research. Journal of International Women's Studies, 3(2)

Ghai, Anita (2003). Disembodied Form: Issues of Disabled Women. New Delhi: Har-Anand Publications

Goffman, Erving (1993). Stigma: Some notes on the management of spoiled identity. Englewood Cliffs, N.G: Prentice-Hall

Gudavarthy, Ajay and Nissim Mannathukkaren (2014). The Politics of Secular Sectarianism. Economic and Political Weekly, 49 (39). www.epw.in last accessed on 18.12.2018

Hasan, Zoya and Ritu Menon (2005). Unequal Citizens: A Study of Muslim Women in India. New Delhi: Oxford University Press

Hosseini-Mir, Ziba. (1999). Islam and Gender: The Religious Debate in Contemporary Iran. New York: Princeton University Press

Harding, Sandra (1987). Is there a Feminist Method? In: Feminism and Methodology: Social Sciences Issues, edited by Sandra Harding, 1-15. Bloomington and Indianapolis: Indiana University Press

Haraway, Donna (1988). Situated Knowledges: The Science Question in Feminism and the Privilege of Partial Perspective. Feminist Studies, 14(3): 575-599

Kakoti Borah, Poonam(2018). Engaging with the Law: Decriminalisation of Homosexuality and 
the Johar Judgement, 2018. Journal Space and Culture, India, 6(3), 5-22.

https://doi.org/10.20896/saci.v6i3.400

Khan, Sameera (2007). Negotiating the mohallaexclusion, identity, and Muslim Women in Mumbai. Economic and Political Weekly,42(17):1527-1533

Kirmani, Nida (2013). Questioning the Muslim Woman: Identity and Insecurity in an Urban Indian Locality. New Delhi: Routledge

Kovach, Margaret., Jeannine Carriere., M.J.Barrett., Harpell Montgomery., and Carment Gillies. (2013). Stories of Diverse Identity Locations in Indigenous research. International Review of Qualitative Research, 6(4): 487-509. www.jstor.org/stable/10.1525 last accessed on 05.11.2018

Linton, Simi (1998). Disability studies/ Not Disability Studies, Disability and Society, 13( 4):525-40

Lyotard, Jean-Francis, (1984). The Postmodern Condition: A Report on Knowledge. Geoff Bennington and Brian Jameson, Trans. Minneapolis: University of Minnesota Press

Mahmood, Saba (2005). Politics of Piety: The Islamic Revival and the Feminist Subject. Princeton: Princeton University Press

Mehrotra, Nilika (2011). Disability Rights Movements in India: Politics and Practice. Economic and Political Weekly, 46 (6): 65-72 https://www.jstor.org/stable/27918121 accessed on 5.11 .18

Mehrotra, Nilika (2012). Disability Rights Movements in India: Politics and Practice. Economic and Political Weekly, 46( 6): 65-72 https://www.jstor.org/stable/27918121 accessed on 5.11 .18

Mehrotra, Nilika (2012). Methodological Issues in Disability Research: An Introduction. Indian Anthropologist, 42(1):1-10 https://www.jstor.org/stable/41922004 last accessed on 5.11.2018

Miles, M. (2002). Community and Individual Response to Disablement in South Asian
Histories: Old Traditions and New Myths. Asia Specific Disability Rehabilitation Journal

Mohanty, Talpade Chandra (2003). Feminism Without Borders: Decolonizing Theory, Practicing Solidarity. New Delhi: Zubaan

McNabb, E. D. (2004). Research Methods for Political Science, Quantitative and Qualitative Methods. New Delhi: PHI Learning Private Limited

Reddy, Raghava (2011). From Impairment to Disability and Beyond: Critical Explorations in Disability Studies. Sociological Bulletin, 60(2): 287-306 www.jsor.orglast accessed on 5.11 .2018

Mondal, Saptarshi (2010). Adjudicating Disability: Some Emerging Questions. In Economic and Political Weekly, 45( 49):22-25 www.jsor.org last accessed on 5.11.2018

Shawn, Wilson (2001). What is Indigenous Research Methodology? In Canadian Journal of Native Education, 25(2): 175 www.researchgate.netlast accessed on $14 / 12 / 18$

Sing, Rajendra (2001). Social Movements, Old and New: A Post-Modernist Critique. New Delhi: Sage Publications

Somekh, Bridget., and Cathy Lewin (2012). Research in the Social Sciences. Theory and Methods in Social Science Research edited by Bridget Somekh and Cathy Lewin, 1-15. New Delhi: Sage Publications

Smith, Tuhiwai Linda (1999). Decolonizing Methodologies: Research and Indigenous Peoples. London: Zed Books

Sur, Esita (2018). Triple Talaq Bill in India: Muslim Women as Political Subjects and Victims?. Journal Space and Culture, India, $5(3): 5-$ 12.https://doi.org/10.20896/saci.v5i3.299

Porsanger, Jelena (2004). An Essay About Indigenous Methodology .https://uit.no/go/target/596504last accessed on 24.02.2019

Pryse, Marjorle (2000). Trans/Feminist Methodology: Bridges to Interdisciplinary 
Thinking. NWSA Journal, 12(2):105-118 www.jstor.org/stable/4316739

Press Trust of India. (2nd January 2019). Triple talaq bill anti-women, says women's wing of AIMPLB .http://timesofindia.indiatimes.com/articlesh ow/67343514 last accessed on 05.11.2018

Said, Edward (1978). Orientalism. New Delhi: Pantheon Books

Sen, Samita and Nandita Dhawan (2011). Feminism and Politics of Gender: A History of the Indian Women's Movement. In Mapping the Field: Gender Relations in Contemporary India, edited by Nirmala Banerjee, Samita Sen and Nandita Dhawan, 1-40. Kolkata: Stree Publications.
Richardson, A. Troy. (2015). Indigenous Methodologies and Educational Research for Meaningful Change: Parsing Post positivist Philosophy of Science and Mix Methods in Collaborative Research Settings. Journal of American Indian Education, 54 (1):33-62 www.jstor.org/stable/10.5749

Weber, Cora., and PillWax. (1999). Indigenous Research Methodology: Exploratory Discussion of an Elusive Subject. The Journal of Education Thought, 33(1):31-45 www.jstor.org/stable/23767587 last accessed on 24.01.2019

Yuval-Davis, Nira (2011). The Politics of Belonging: Intersectional Contestations. New Delhi: Sage Publications. 